\title{
Basic Study on the Assembly Process Design of Curtain-wall System for Minimization of Carbon Emission
}

\author{
Yi, June-Seong* \\ Department of Architectural Engineering, Ewha Womans University, Seodaemun-Gu, Seoul, 120-750, Korea
}

\begin{abstract}
With recent attempts to improve quality and productivity, the prefabrication manufacturing system has been occupying an increasing share of the construction area. To minimize site work, material is more frequently being produced and partially assembled at a plant, and then installed at a site. For this reason, the production process is being divided and the materials are being delivered to the site after passing through multiple plants. With these changes in the production process, the materials delivery plan is becoming an important management point. In particular, as road transportation using trucks has a 71 percent share of the domestic transportation market, selecting the proper transportation path is important when delivering materials and equipment to a site. But the management system at the project design phase to calculate the delivery cost by considering the production process of the pre-fab material and the $\mathrm{CO}_{2}$ emission at the material delivery phase is currently lacking. This study suggests a process design model for assembly production of the pre-fab material and transportation logistics based on carbon emission. The suggested model can be helpful to optimize the location of the intermediate plant. It is expected to be utilized as a basic model at the project plan and design phase when subcontractors make decisions on items such as materials procurement, selecting the production method, and choosing the location of the assembly plant.
\end{abstract}

Keywords : pre-fabrication, process design, carbon reduction

\section{Introduction}

\subsection{Rsearch background and objective}

Deliverables including materials and equipment are transported to a construction site to complete a construction contract. In addition, construction projects require seamless cooperation among several companies specialized in specific fields[1]. Recently, the prefabrication method has been introduced to the construction field for the purpose of improving quality and productivity, and prefabricated materials

Received : September 14, 2012

Revision received : October 2, 2012

Accepted : October 9, 2012

* Corresponding author : Yi, June-Seong

[Tel: 82-02-3277-4454, E-mail: jsyi@ewha.ac.kr]

(c)2012 The Korea Institute of Building Construction, All rights reserved. are being assembled at the site in an attempt to minimize work at site. With modular construction using external panels and light-weight steel frame being applied to more structures, the application of prefabrication is now being extended from single materials to composite materials. For this reason, the production process of construction materials is divided, and the materials pass through multiple plants before reaching a construction site.

In addition, it is reported that transport accounts for $20 \%$ of the $\mathrm{CO}_{2}$ emissions produced by the entire energy sector in Korea, and in particular, transport by truck amounts to $71 \%$ of the entire domestic transport. However, the carbon emission generated during transport of materials has not been sufficiently taken into account considering the transport sector's impact on the 
environment. More specifically, no cost estimation and management system has been established that considers the order of prefab processes and carbon emission from the construction planning phase.

Thus, this paper aims to propose a process design model that considers environmental costs and transportation costs according to the location of intermediate plants, in order to assist in decision-making on the production and assembly method of prefab construction materials. It is expected that the model proposed in this study can be utilized as a yardstick in establishing a strategy for supply chain management, including materials procurement, production, and selection of method and location of plants at the business planning and design phases.

\subsection{Research method and scope}

The aim of this study is to present 'a production process design model to minimize carbon emission related with prefabricated materials,' by selecting the optimal material production method and location of intermediate production plants based on a comparison of environmental costs considering the impact of travel distance on carbon emission.

The major interest of this study lies in comparing transport cost by production method and the carbon cost accompanying the transport process of prefabricated materials, and it is assumed that there are no differences between the prefab method and the alternatives in terms of general logistics cost and production cost of materials. To examine the validity of the suggested model, the aluminum curtain wall produced at a factory is selected, and the transport of the prefabricated materials is limited only to road freight transport.

The process of this research is as follows:

1) Through a review of previous studies, the production trend of construction materials and the impact on the environment of transport are researched from an SCM (Supply Chain Management) perspective, and basic concepts of a production process design model to minimize the carbon emission related with the transport of prefabricated materials are established.

2) A flow of the transport path reflecting the divided assembly production method of prefabricated materials and a carbon emission estimation process are drawn to build a mathematical model for general carbon emission estimation encompassing the entire transport path, including not only the transport paths between plants located at the midpoint but also the path to the final construction site. Based on the mathematical model, the optimal process design model is presented to minimize carbon emission in all phases, from prefabrication to transport and to installation.

3) To verify the applicability of the proposed model, the production process of the unit type aluminum curtain wall is analyzed, since the unit type aluminum curtain wall is a representative prefabricated exterior material. A scenario reflecting the transport path by production method is made, and the total cost is estimated considering the transport cost and carbon emissions for each alternative.

4) The most effective plan is selected depending on the production method and the location of plants located at the midpoint (production and assembly) by comparing the total cost of alternatives. In addition, the factor influencing the total cost most is determined through a sensitivity analysis to elicit the most important management factor in 
designing the production process.

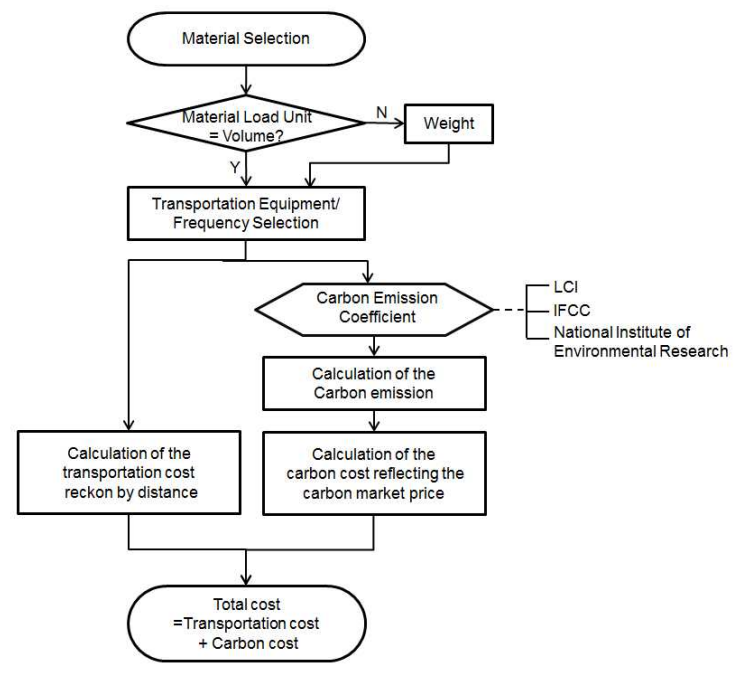

Figure 1. Flow for calculation of the total cost

\section{Theoretical review and concept definition}

\subsection{Relationship of the production trend of construction materials with transport}

In construction, the concept of prefabrication refers to a series of production processes for producing parts of components under the plant production system. The whole unit or member should be easily produced, assembled and installed at the site. On the other hand, it also refers to a modularized and standardized construction member or a finished structure produced and assembled using the members prefabricated in a plant in advance[2]. Likewise, prefabrication enables the rapid and effective mass production of standardized construction materials and members through the standardized production process, reducing production cost accordingly, and as such it has been the subject of keen interest by the construction industry[3].

Prefabricated materials and members require minimal work at site, and thus are quite compatible with attempts to minimize site works.
In addition, the modular method using exterior panels and lightweight steel frame is in wide application, from single materials to composite materials. Likewise, as the design market for the prefab construction system has been expanding and the demands for the prefabricated materials including the modular method have been on the rise, the production process of construction materials is divided, and the materials pass through multiple plants before being delivered to a construction site, which brought about a drastic increase in freight transport. In addition, considering that road transport by truck represents an increasing share of the logistics transport, a more efficient transport path should be selected at the construction planning phase due to the large quantity of construction materials and equipment carried into a construction site by truck.

For the successful implementation of a construction project, material logistics that enable the materials prefabricated in a plant delivered as planned on schedule to cope with the flexible environment factor of the site are important[4]. The transport path of prefabricated materials is selected based on the location of the plants located at the midpoint and the construction site, and is also affected by the quantity of materials needed and the distribution of production plants. To derive the optimal material transport path, a decision-making support system should be provided in which the opinions of users are reflected and on which basis the users can make a decision[5]. Many studies have been conducted from diverse perspectives, and these can be referred to when attempting to determine the optimal transport path. Figueiredo et al.[6] presented a design plan for minimum-cost recycling collection networks to achieve the throughput and appropriate location of the recycling center and the recycling level 
required by legal regulations,

Erkut et al.[7] drew the transport path of a hazardous vehicle through a risk analysis by minimizing various objective values. Kim EM[8] analyzed distribution channel types by material based on research data on the existing distribution paths of target items. When the destination is a construction site, the distribution path can be divided into direct transport and layover transport. Through a comprehensive analysis of related studies, it was found that there is a close parallel between the process of selection of plants located at the midpoint and the process for the selection of logistics centers. That is, the path is selected based on the locations of the destination, the construction site and the plants located at the midpoint, similar to logistics centers in a general logistics path, and the selection of the path is also affected by the distribution of plants located at the midpoint and the quantity of construction materials needed. Due to the nature of the construction business, it is important to select the optimal transport path by considering the construction site and the plants located at the midpoint of the materials needed.

Studies have been actively conducted to satisfy multiple criteria, including minimization of travel distance, minimization of transport cost, minimization of transport time, minimization of exposure to an accident, or risk design requirements of logistics networks on which basis the number and the locations of bases or plants and facilities are determined. The theoretical review was conducted in a wide range, to draw the transport path by comprehensively selecting the optimal order of production and delivery processes considering the locations of the construction site and plants located at the midpoint and the travel distance based on the cost range estimation for each assembly production method.

\subsection{Impact on the environment of material transport}

Construction is operating under the order production system, which means that the construction business is an order-made production industry, in which an order is placed first and then the construction is performed later. The output should be placed in the specific space required by the client, and the materials and equipment should be moved to the site to implement the construction, making it different from other industries. A contractor shares a construction project with other participants to produce the contracted object in an effective manner. For this reason, the construction project tends to involve a division of labor between participants. More specifically, the contractor outsources professional and materials required for production in a timely manner and at a reasonable price to lead the project to success[9]. When the split production method was introduced, it was initially restricted to the production process within a company. However, as capitalism has intensified, this split production system is extending even up to the level of firms.

The success of split production and collaboration can be explained from the perspective of supply chain management (SCM), and the research related to construction materials production and transport has also been mainly conducted in terms of the supply chain. SCM in the construction field considers production activities of all participants, including contractor, designer, builder and material supplier, as a production system, and integrates and optimizes the production system by activating the flows of resources, information and capital for the ultimate purpose of improving the efficiency of the entire system[10]. Agapiou et al.[11] put a 
particular emphasis on the importance of communication and information exchange between members in the supply channel to manage diverse flows related to materials. Likewise, previous studies on the SCM of construction materials mostly focused on communication and information sharing, and the transport path, which plays an important part in the supply network, has not yet been fully considered and reflected.

Faulin et al.[12] considered the environmental cost as a variable, not to mention the distance, cost, the number of vehicles and profit to get the optimized freight transport path. With the values presented in the environment pollution criteria for diesel trucks prepared by EURO and heuristic algorithms, an algorithm with environmental criteria (ACE) was developed that provides a quotation of environmental cost, and calculates the traditional cost based on an actual scenario. However, it was used to determine the appropriate path for delivery of a product to customers, and is evaluated as not appropriate for the path with a fixed sequence of prefabricated materials.

In Korea, freight forms a considerable part of road transport, and when planning a transport network, the work is mostly done based on the worker's personal skill and expertise. In addition, after the transport plan is established, only the final results (transport cost, transport time, etc.) are presented to a consignor, with no explanation for the deduction process, and few alternatives are presented. In these circumstances, it is difficult to calculate the impact on the environment of each transport alternative. For this reason, a system should be built that enables the continuous accumulation of knowledge and data on previous path planning and expertise on transport network planning from a long-term perspective.

\section{Process design modeling for selection of a material assembly method}

\subsection{Establishment of a basic mathematical model}

In this study, a mathematical model of the transport process was established according to the production method (sequence of assembly process) of prefabricated assembly materials, and a process design model was presented that determines a distributed production method using an algorithm that minimizes the transport cost depending on the locations of plants at the midpoint. The fragmentation of the material production line and the transport model deals with the batch production system by which all the processes are done at the manufacturing and production phases and the distributed production system by which part or all of each process is outsourced, and focuses on comparing the transport cost generated in the course of transport of the produced materials from plant to site.

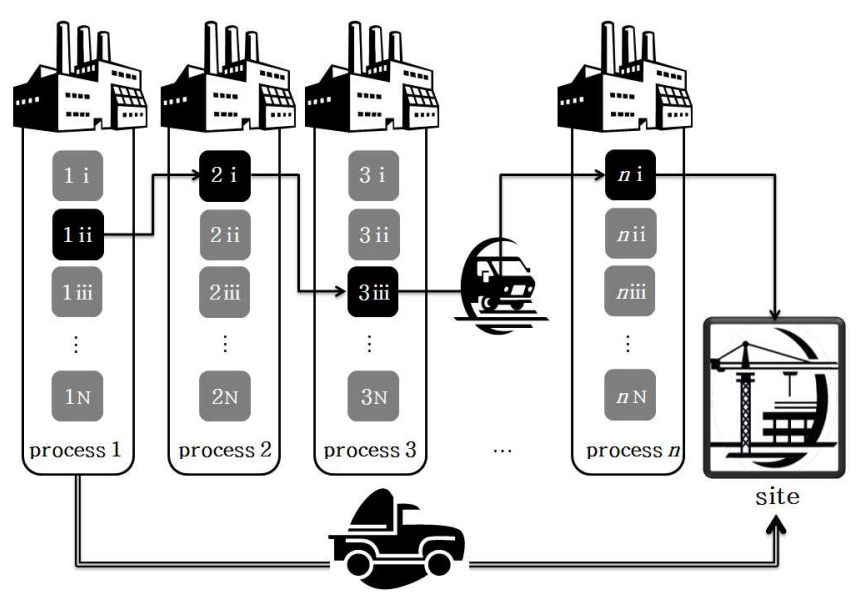

Figure 2. Conceptual diagram of material production and transportation

As illustrated in Figure 2, the production process of the material to be transported to a construction site is carried out in order of $1,2,3 \cdots, n$. The candidate plants that can handle Process 1 are 
expressed in a sequence starting from $1 \mathrm{i}$ to $1 \mathrm{n}$ (1i, 1ii, 1ii, $\cdots$, n). A decision-maker randomly selects a plant from among the candidates (1ii in the Figure 1). The solid line indicates a distributed production system via several processes, and the double solid line indicates the batch production system by which all production is completed in 'Process 1 ' at the plant of 1 ii and transported to the construction site.

When the decision-maker chooses 1 ii for 'Process 1' as shown in Figure 2, the plant produces the assigned assembly material, and checks the completeness of assembly. If the assigned material is not a finished material, it is transported to another plant for the subsequent process (2i in Figure 2), and additional cost is incurred in the course of transport between plants. If the assigned material is not a finished material, it is transported to another plant for the subsequent process (3iii in Figure 2), and additional cost is incurred in the course of transport between plants. This procedure is repeated until the material becomes a finished good, which is then transported to the construction site. The procedure is a general flow of the distributed production system. When produced using the batch production system, the finished goods are produced in 1ii, and are transported directly to the construction site, and the transport cost is incurred just once.

A. Parameters

: Process node $(\mathrm{i}=1,2, \cdots, \mathrm{n})$

: Transport cost of a vehicle from node i-1 to node I

: Transport cost of a vehicle from the final node $\mathrm{n}$ to the construction site(s)

: The total number of vehicles used for transport from node $\mathrm{i}-1$ to node $\mathrm{i}$

: The total number of vehicles used for the transport from node $\mathrm{n}$ to the construction site(s)

: Carbon cost by vehicle arising from the transport from node i-1 to node i

: Carbon cost by vehicle arising from the transport from node $\mathrm{n}$ to the construction site(s)

B. Decision Variables

: When selected as the production plant, 1 is given. When not selected as the production plant, 0 is given.

: Cumulative completeness (\%)

C. Objective function

$$
\begin{aligned}
\mathrm{D} & =\sum_{i=2}^{n} D_{i} X_{i} Y_{i}+X_{n s} D_{n s}------\mathrm{Eq} . \\
\mathrm{E} & =\sum_{i=2}^{n} E_{i} X_{i} Y_{i}+X_{n s} E_{n s}------\mathrm{Eq} .
\end{aligned}
$$

Eq. (1) expresses the total transport cost by comprehensively considering the transport costs arising from transport to the plants located at the midpoint and to the destination, the construction site. On the other hand, Eq. (2) expresses the carbon cost incurred in the course of layover to the plants located at the midpoint selected in the production system.

D. Constraint equation

$$
P_{i} \leq 100 \quad \text { Eq. }
$$

Eq. (3) expresses that the cumulative completeness cannot exceed $100 \%$, as when the completeness reaches $100 \%$, it will be transported to the construction site.

\subsection{Cost estimation criteria}

The transport cost is determined based on distance and vehicle method, but is occasionally based on the chartered transport fare presented in 
a standard of estimation. In this study, we divided the production system of prefabricated materials into a batch production system and a distributed production system. In the batch production system, finished prefabricated materials are produced in the production and assembly phases, while in the distributed production system part or all of each process is outsourced to produce finished prefabricated materials. For the distributed production system, a series of plants located at the midpoint that carry out a detailed production process are determined by a decision maker considering the entire production sequence. When completing the production process in a plant, the completeness is checked before transfer to the subsequent plant (or the construction site). When the materials are transported, either to the subsequent factory or to the construction site depending on whether they are in finished or unfinished condition, the transport cost and carbon emission are calculated depending on the next destination.

Transport cost is generally determined based on type of transport equipment and distance between the origin and the destination, and the purpose of this study is to enable a decision maker to make a plan for the production system that comprehensively considers transport cost and carbon emission cost. To make a model utilized in decision making at an early business planning phase that determines type of dry material and production method, uncertain variables should be thoroughly considered in the estimation of carbon emission cost. For example, the variables include the certified mileage considered in estimating fuel assumption, and velocity at the coefficient of discharge presented by the Korea Institute of Environmental Research. However, the certified mileage is presented as higher than actual mileage, and mileage varies depending on driving habits and road conditions. In terms of the velocity, it continued to fluctuate because the vehicles did not move at a constant speed on the given road. For an analysis of potential uncertainty, the 2006 IPCC Guideline[13] provided the guidelines for uncertainty estimation, and its report presented two approaches to combining estimated uncertainties. Approach 1 is a spreadsheet-based simple calculation process based on basic assumptions for the purpose of simplification of calculation. Approach 2 is a Monte Carlo simulation-based methodology that is more applicable to general use. Therefore, to conduct a Monte Carlo analysis, software such as MS Excel, @Risk, and CrystalBall can be considered. The purpose of the integrated model of material production and transport (Eq.) is to support a comparison between alternatives.

$$
\begin{aligned}
& \mathrm{T}=\min \sum(D+E) \\
\mathrm{D}= & \sum_{i=?}^{n} D_{i} X_{i} Y_{i}+X_{n s} D_{n s} \\
\mathrm{E}= & \sum_{i=2}^{n} E_{i} X_{i} Y_{i}+X_{n s} E_{n s}
\end{aligned}
$$

$\mathrm{T}$ : total cost

D: total transport cost

$\mathrm{E}$ : total carbon cost

\section{Selection of a target material and basic assumptions for the model verification}

\subsection{Selection of a target material and analysis of the production system}

1) Reasons for the selection

Curtain walls are now being employed in Korean high-rise building construction projects more frequently than ever before. In terms of 
investment cost, curtain wall installation generally represents $10 \%-15 \%$ of the total construction cost, which is considerably high compared to other processes. In terms of process management, it is placed in the critical path connected back and forth with framework and diverse types of finishing work. In addition, to install a curtain wall, a large quantity of materials should be delivered to the site from outside, and repetitive work should be carried out[14]. As the curtain wall is a long lead time item, which means that a relatively long time is required to procure materials to the site from the production plant, JIT (just-in-time) management is required[15]. The following are the material logistics issues related with the curtain wall installation found in previous studies.

First, an increase in the travel time and distance between plants that carry out processes such as extrusion, painting, assembly, and glazing may cause the material delivery to be behind schedule. Second, if an inappropriate plant has been selected in the process of selection, while the original intent may have been to improve productivity, an increased logistics cost may result due to the increase in travel distance caused by the distribution of production plants. In this study, the problems are dealt with by selecting appropriate manufacturers and production system at an early planning phase, in accordance with the object of the model presented in Chapter 3 .

To examine the validity of the process design model for dry material production, the curtain wall was selected as the target material. Curtain walls are generally classified by material, installation method, and type. By material, curtain walls can be classified into curtain wall, glass and aluminum curtain wall, concrete curtain wall, and metal curtain wall. By installation method and shape, curtain walls can be classified into stick type curtain wall and unit type curtain wall. The stick type curtain wall is assembled and then installed at the site, while the unit type curtain wall, produced as a completely assembled wall in a plant, is installed at a site without assembly. The unit type curtain wall is most widely employed in high-rise buildings. It is effective in terms of reducing the construction duration, but its weight per unit is heavy, and comprehensive and careful consideration should be given to the transport and lifting of the unit. The validity of the proposed model is examined using the unit type glass and aluminum curtain wall made using the layer method, as it can be easily maintained, formed in diverse shapes, and facilitates high-rise building construction work.

2) Analysis of the curtain wall production system

As illustrated in Figure 3, the working process carried out by a curtain wall company is divided by work type. The working process can be largely divided into construction-centered work including design of curtain wall members and system, delivery and lifting, and installation at the site, while manufacturing-centered work includes member production and assembly. The production system can also be divided into a batch production system by which all work units (extrusion, painting, assembly and processing, glazing, etc.) are carried out in a single plant, and a distributed production system by which part or all of each of the work units is outsourced. In recent years, to take advantage of cost reductions and the specialization of manufacturing and production systems, the distributed production system has been increasingly adopted[16].

The production process of the unit type system can be more specifically classified into mold, extrusion, painting, processing and assembly, 


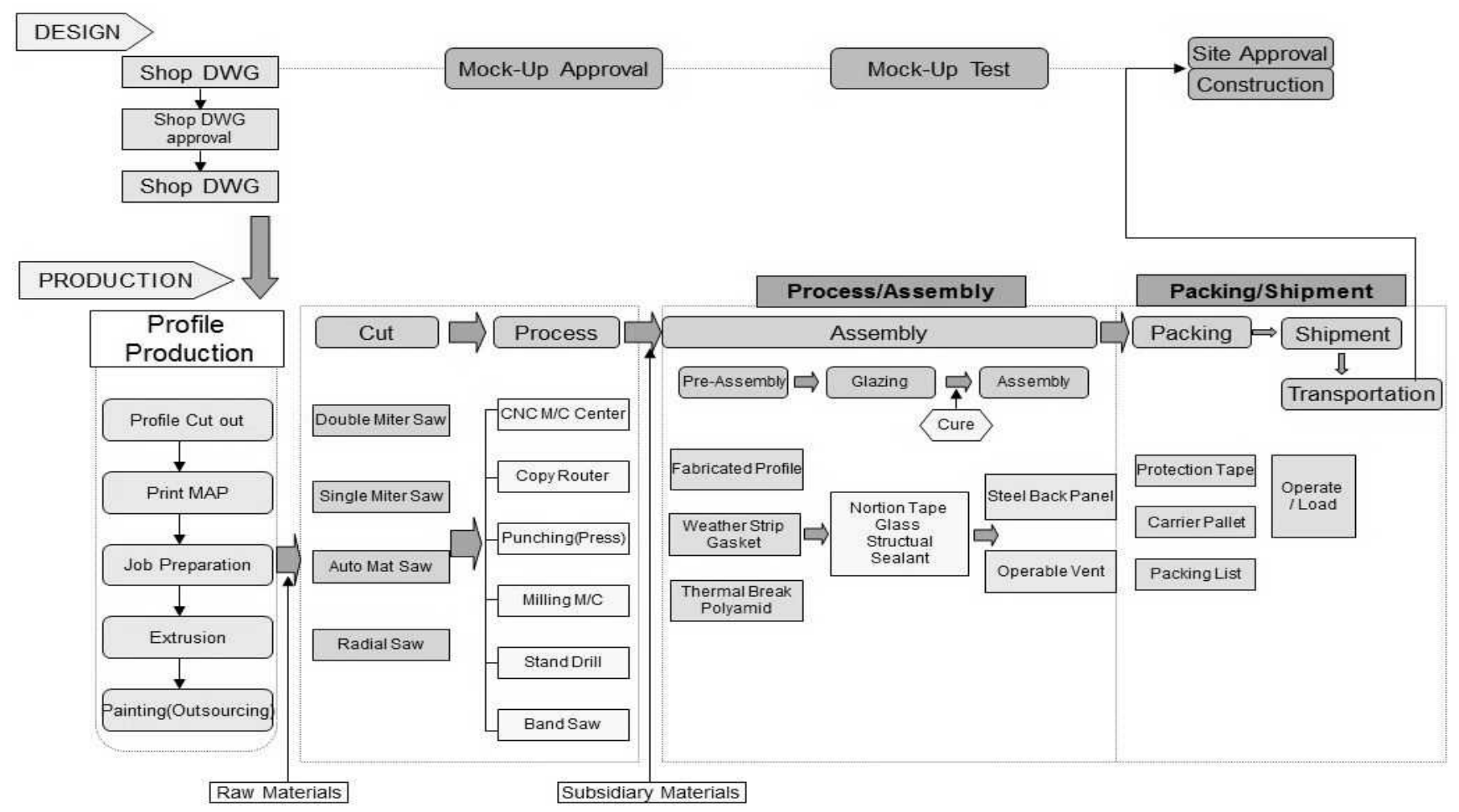

Figure 3. Manufacturing Process (Curtain-wall Installation Plan)

glazing, and packaging and shipping. Extrusion, painting and processing and assembly are required for the production of aluminum panels, extruded bars, and aluminum boards. Double layer glass is required for glazing. Glazing is the work of connecting the double layer glass with the curtain wall assembled with aluminum panels and extruded bars, and can be done either in a glass processing plant or in a curtain wall assembly plant.

\subsection{Basic assumptions by alternative for the process design model}

\subsubsection{Basic assumptions}

The process design model proposed in this study was applied to the unit-type aluminum curtain wall installation to perform a comparative analysis of alternatives. The following are the basic assumptions made for the analysis.
Table 1. Basic assumptions for the model verification

\begin{tabular}{cc}
\hline Category & Basic Assumption \\
\hline $\begin{array}{c}\text { Production } \\
\text { method }\end{array}$ & Method2 : Distributed production process \\
& Method3 : Pre-glazing distributed production \\
process
\end{tabular}


First, the production method of the unit type aluminum curtain wall can be broadly categorized into a batch production system (Method 1) and a distributed production system. The distributed production system can be more specifically divided into two work groups (Method 2 and Method 3). Method 1 is a batch production system by which all the production processes including extrusion, painting, assembling and processing, and glazing are carried out in one plant, and the finished materials are carried into the construction site. As mentioned previously, the distributed production system can be divided into two work groups: aluminum panel assembly and glazing. In Method 2 , the aluminum panel assembly is carried out, from production, extrusion, painting and assembly to processing of the aluminum materials (extruded bars, aluminum panels, aluminum board). Then, the intermediate products are transferred to the next plant for double glazing works, and then the finished materials are carried into the construction site. In Method 3, the glass related work is implemented first, including cutting the plate glass and double glazing production. Then, the finished glass is transferred to the next plant, and the aluminum panel production work is done in the plant.

The curtain wall production system is divided in this manner to reflect the current production situation in which the production and assembly process of the aluminum panel/ aluminum bars, and glass product production process are outsourced. Of the processes, the aluminum related process is simplified, the aluminum panels and bars that form the curtain wall frame are produced in a plant, and the finished curtain wall frame is carried into the construction site.

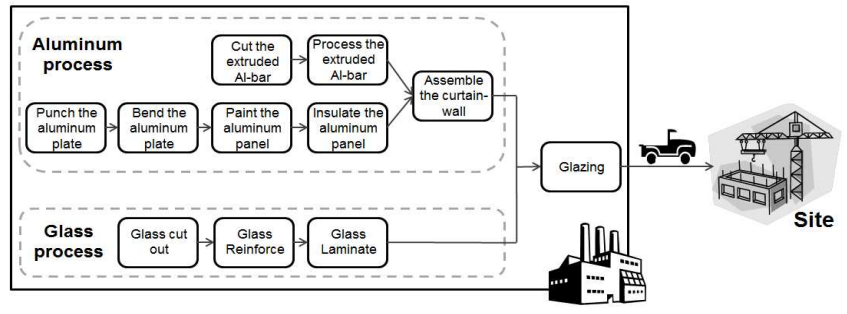

(a) Batch production process (Method1)

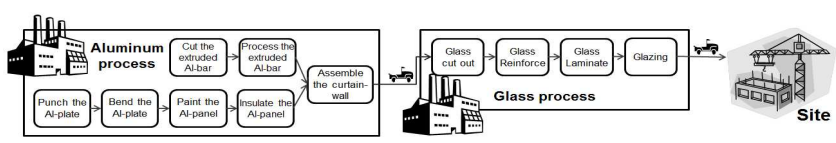

(b) Distributed production process (Method2)

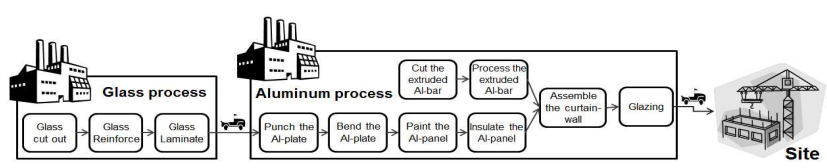

(c) Pre-glazing Distributed production process (Method3)

Figure 4. Schematized model of the production process

Second, the basic unit dimension of the unit type curtain wall was set at $1200 \mathrm{~mm} \times 3200 \mathrm{mmx} 160 \mathrm{~mm}$, and the pair glass thickness was set at $24 \mathrm{~mm}$. The unit weight was set at $150 \mathrm{~kg}$, the unit before glazing (aluminum frame) at 100kg, and the double layer glass at $50 \mathrm{~kg}$.

Third, as the loading unit to the transport equipment, volume is used for the finished aluminum frame and aluminum curtain wall, and weight for glass products,

The finished aluminum frame and aluminum curtain walls are fixed to the pallet and transported. When loading, 5 units are placed on a pallet, and 4 pallets are loaded on a 5-ton truck, for 20 units loaded in total.

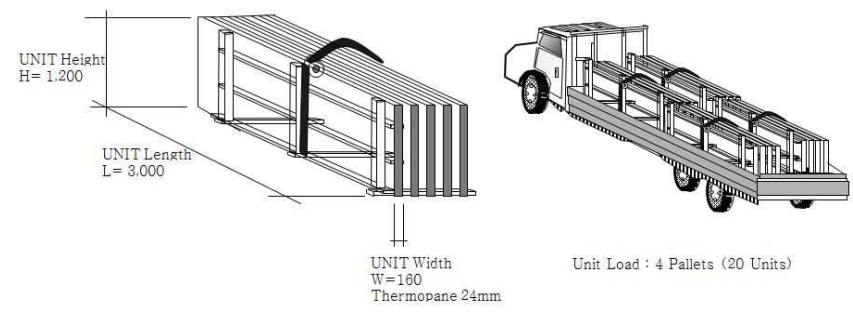

Figure 5. Diagram of the loading units 
Fourth, the material quantity carried in a day is set at 100 units, and 20 units can be loaded on a 5 -ton truck. Therefore, it is assumed that a total of 5 trucks are used. Under the premise that there is no loss to double glazing, it is assumed in this study that a 5-ton truck is used, although 100 units weighing $5000 \mathrm{~kg}$ could be transported using either one 5-ton truck or two 3-ton trucks.

Fifth, five curtain wall production plants are selected all over Korea (Seoul, Goyang, Daejeon, Daegu, and Busan), each of which is assumed to have the equipment required to carry out part or all of the process related with curtain wall production.

Finally, the following is the information on the variables influencing the model.

1) The travel distance is expected to vary depending on the driver's driving habits and road conditions. The beta-PERT distribution has the shortest route searched through a map service as the minimum value, $+5 \mathrm{~km}$ as the expected value, and $+25 \mathrm{~km}$ as the maximum value.

2) Carbon transaction price and exchange rate can fluctuate, soar or plummet depending on the international situation. An appropriate distribution is drawn based on 3-year and 1-year data, and used.

\subsubsection{Basic assumptions by alternative}

The changes of the transport cost and the environment cost generated from the distributed production system is analyzed in consideration of carbon cost to plan a production system that is appropriate for the site conditions or business circumstances. Through a comprehensive cost estimation using the process design model presented in this study, a material supplier can select a distributed production process appropriate for site conditions. That is, it is expected that the material supplier not only can compose the most efficient production system by selecting multiple plants located at midpoint, but can also support the final products to be delivered to the destination on schedule using the optimal transport network.

A supplier can select one from many alternatives generated from the combination of the production system (Method 1, Method 2, Method 3) and plants located at midpoint (5 plants); however, the purpose of this study is to examine changes in total cost by alternative (combination of assembly process plan and plant location). For this reason, a plant located in the city of Goyang was set as the initial production point and the construction site was set in Busan. Five locations (Icheon, Nonsan, Okcheon, Daegu and Gumi) were applied to the alternative comparison, and the central area of each city was set as a datum point. The transport cost was estimated by applying the rate by distance based on the freight rates set by each location, as well as the vehicle (5-ton truck). In addition, the carbon cost was estimated by applying the carbon emission coefficient of a general road provided by the Korea Institution of Environmental Research, the EU-ETS carbon transaction price and the Euro exchange rate.

Table 2. Default value of the scenario application

\begin{tabular}{|c|c|c|}
\hline Category & \multicolumn{2}{|c|}{ Details } \\
\hline $\begin{array}{l}\text { Transportation } \\
\text { equipment }\end{array}$ & \multicolumn{2}{|c|}{ 5ton truck } \\
\hline $\begin{array}{l}\text { transportation } \\
\text { cost }\end{array}$ & \multicolumn{2}{|c|}{ Standard : freight tariff } \\
\hline $\begin{array}{l}\text { Initial point of } \\
\text { the production }\end{array}$ & \multicolumn{2}{|c|}{ the plant located in Goyang-si, Gyeonggi-do } \\
\hline $\begin{array}{l}\text { Plants located } \\
\text { at the } \\
\text { midpoint }\end{array}$ & \multicolumn{2}{|c|}{ Incheon, Nonsan, Okcheon, Daegu, Gumi } \\
\hline Site & \multicolumn{2}{|c|}{ Busan } \\
\hline \multirow{3}{*}{ Transportation } & $\begin{array}{c}\text { Method } 1 \\
\text { (Batch production) }\end{array}$ & 5 trucks $(3000 \mathrm{~kg})$ \\
\hline & $\begin{array}{c}\text { Method } 2 \\
\text { (distributed production) }\end{array}$ & $\begin{array}{l}5 \text { trucks }(2000 \mathrm{~kg}), \\
5 \text { trucks }(3000 \mathrm{~kg})\end{array}$ \\
\hline & $\begin{array}{c}\text { Method } 3 \\
\text { (Pre-glazing distributed } \\
\text { production) }\end{array}$ & $\begin{array}{l}1 \text { truck }(5000 \mathrm{~kg}), \\
5 \text { trucks }(3000 \mathrm{~kg})\end{array}$ \\
\hline
\end{tabular}




\section{Implementation analysis by alternative}

\subsection{Cost analysis by production system}

To examine changes in the total cost according to the distributed production method of the aluminum curtain wall and the location of the plants at midpoint, as mentioned in 4.2 three production methods were selected (a batch production, distributed production, pre-glazing distributed production). To identify the change in cost according to the assembly production method, Method 2 and Method 3 were individually compared with Method 1(batch production) (Figures 6 and 7). A comparative analysis was conducted in terms of carbon cost and total cost (carbon cost and transport cost) on which basis it is expected to predict what will happen if the carbon tax is enhanced in the future.

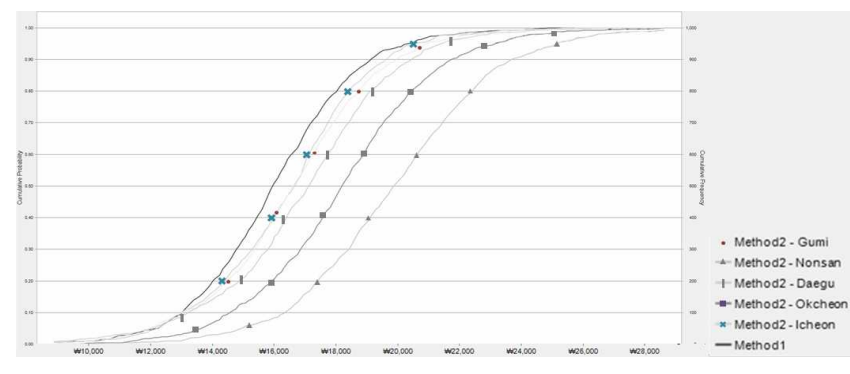

Figure 6. Distribution of Carbon cost to Busan (Methods $1 \& 2$ )

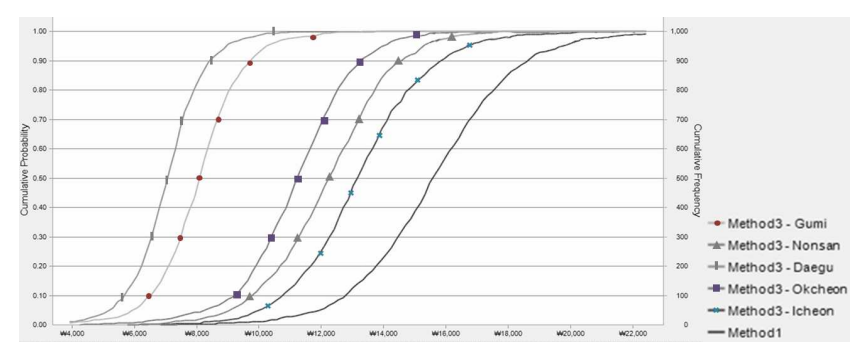

Figure 7. Distribution of Carbon cost to Busan (Methods 1 \& 3)

1) Analysis of carbon cost

In term of the carbon cost generated in the course of transporting the unit type curtain wall from a plant in Goyang to the construction site in
Busan, it was found that when compared with Method 2, the graph of Method 1 is on the left, while compared with Method 3, the graph of Method 1 is on the right. In other words, selecting Method 3 is expected to effectively reduce the carbon cost. At this time, it was found that the most effective location of the plant at midpoint was Daegu, followed in order by Gumi, Okcheon, Nonsan and Icheon. That is, it was determined that the shorter the travel distance, the less the burden of carbon cost.

2) Total cost analysis

The total cost for each alternative was calculated by adding the transport cost between plants to the estimated carbon cost. In terms of total cost, when Method 1 (batch production) was compared with Method 2, Method 1 was shown to be more economic, regardless of the location of the plant at midpoint (Figure 8).

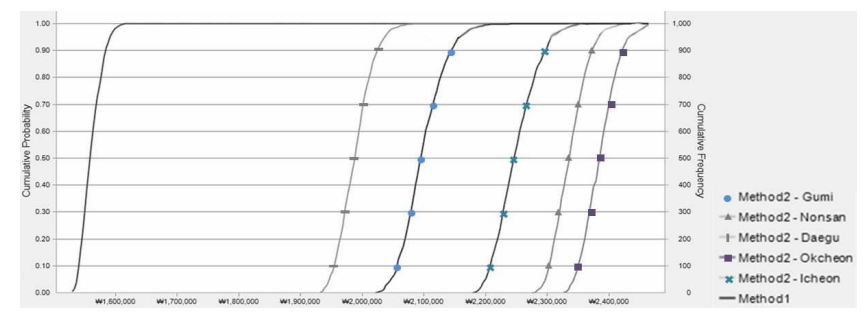

Figure 8. Distribution of Total cost to Busan (Method 1 \& 2)

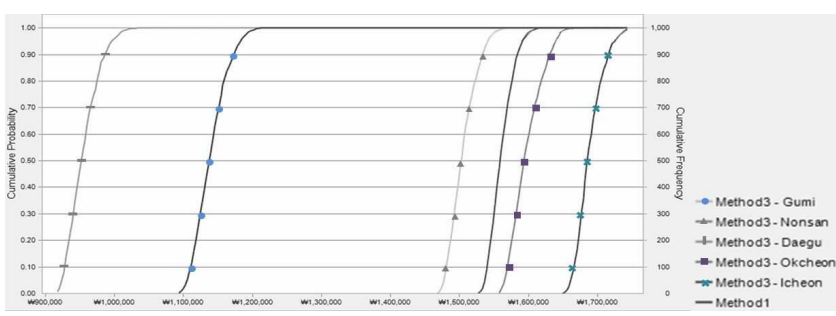

Figure 9. Distribution of Total cost to Busan (Method 1 \& 3)

When Method 1 (batch production) was compared with Method 3 (pre-glazing distributed production) (Figure 9), the results differed slightly depending on the location of a plant at midpoint. When one of Nonsan, Gumi, or Daegu was selected as the 
location of a plant at midpoint, Method 3 was shown to be favorable, while when one of Ichon or Okchoe was selected, the batch production system (Method 1) was evaluated to be more favorable.

\subsection{Sensitivity analysis by factor influencing cost}

The identification of factors that have great impact on cost based on the results of a sensitivity analysis can be utilized as fundamental data in decision-making to establish an assembly production strategy. It is expected that the results might differ slightly depending on the alternative. However, in this chapter, Method 3 (pre-glazing distributed production), which was evaluated to have a better price condition in the total construction cost estimation of the construction site in Busan, was selected, and the location of a plant at midpoint was set at Gumi to perform a sensitivity analysis.

1) Carbon cost related

Figure 10 shows the relative impact of each assumed variable on the expected variable in order. The factor that had a greatest impact on the carbon cost was found to be carbon transaction cost followed by exchange rate, travel distance of finished goods (Gumi-Busan), travel distance of Pre-glazing goods (Goyang-Gumi), and the number of vehicles for Pre-glazing goods.

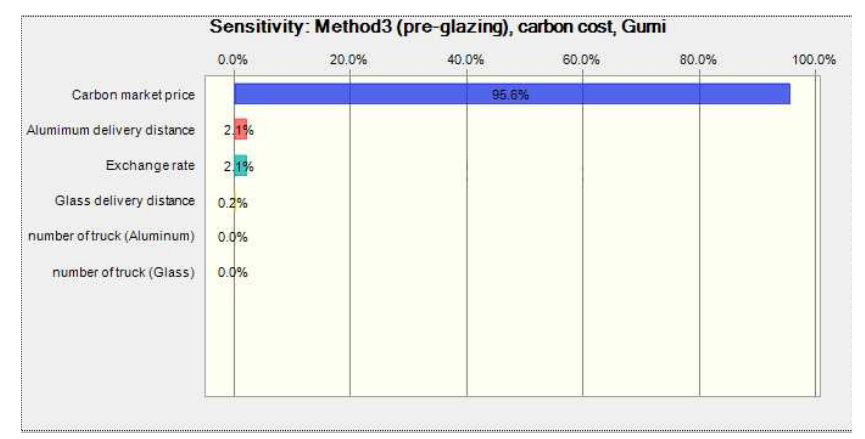

Figure 10. Sensitivity analysis of the carbon cost to site Busan, Method 3 (pre-glazing), when the plant is located at Gumi
A scatter plot is a graph that visually shows the relationship between two variables. That is, based on the shape of scattered dots, the relationship between two variables can be identified. In Figure 11, only carbon transaction cost has a strong positive relationship with the carbon cost, and the other variables are not particularly correlated.

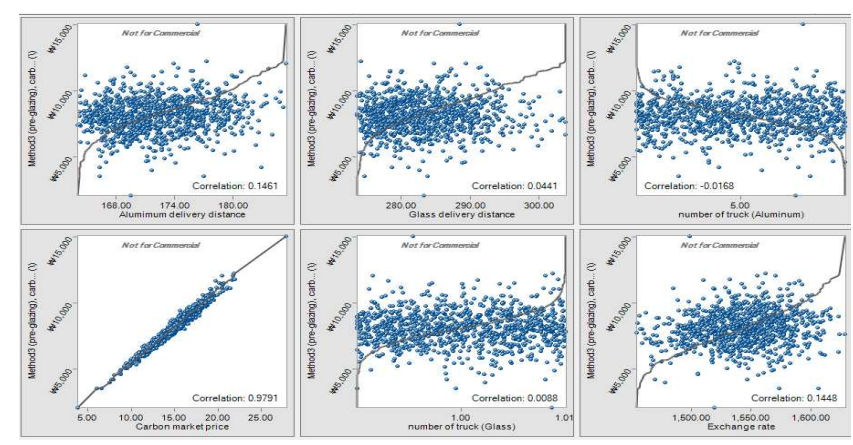

Figure 11. Scatter of the carbon cost to site Busan, Method 3 (pre-glazing), when the plant is located at Gumi

\section{2) Total cost related}

In contrast to the results of carbon cost analysis above, the factor that has the greatest impact on the total cost is the travel distance of finished goods, which is the post process in Method 3(Pre-glazing). In addition, in the scatter plot shown in Figure 13, the travel distance of finished goods shows a strong relationship; thus, it is suggested that the travel distance after the post process should be reduced to reduce the total cost.

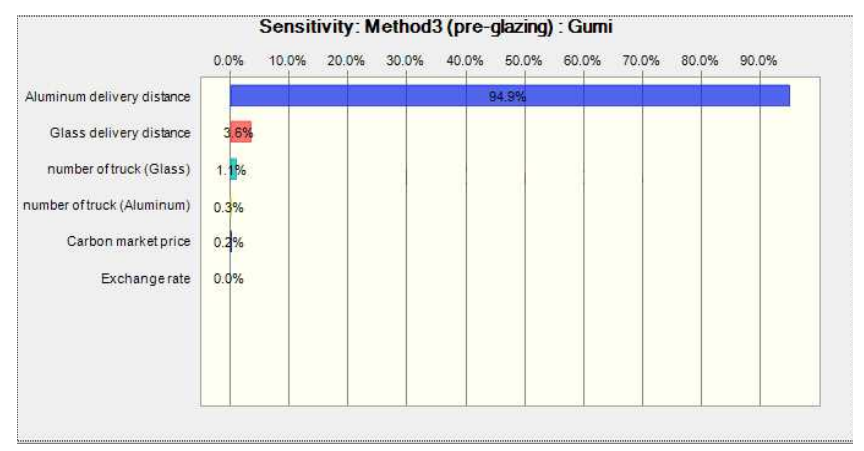

Figure 12. Sensitivity analysis of the total cost to Busan site, Method 3 (pre-glazing), when the plant is located at Gumi 


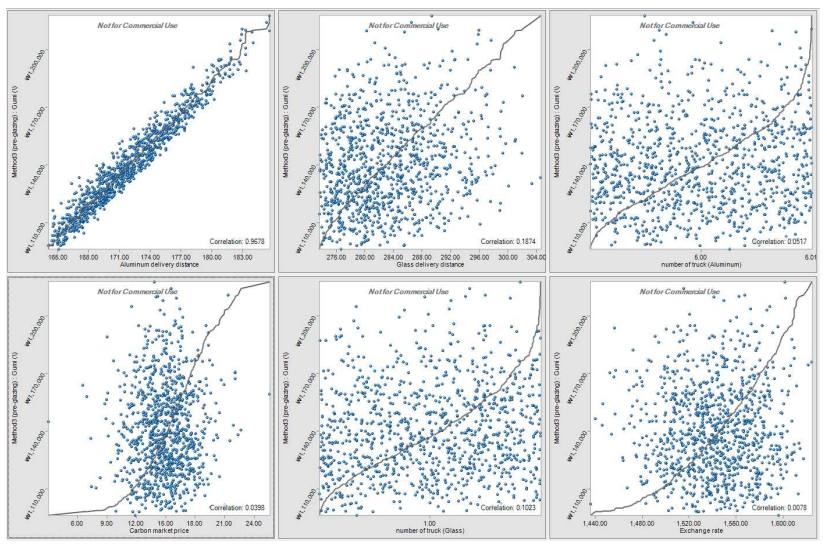

Figure 13. Scatter of the total cost to site Busan, Method3(pre-glazing), when the plant is located at Gumi

\section{Conclusion}

Compulsory reductions in greenhouse gas emissions are being actively discussed worldwide as a countermeasure to global warming. In Korea, attempts to establish a foundation for managing greenhouse gas emissions have been made at the national level. More specifically, the Ministry of Land, Transport and Maritime Affairs distributed guidelines for carbon emission estimation by facility and built a system connected with a DB on greenhouse gas and air pollutant emission: Korea LCI Database Information Network (http://www.edp.or.kr/lcidb/). However, despite keen interest in the manufacturing and production sector, few studies have been conducted on the transport sector. In Korea, carbon dioxide emission by the transport sector accounts for 20\% of the entire energy emission, the carbon emission generated in the course of transport should be considered in early business planning.

In addition, as materials are prefabricated in a plant, composite materials are produced by a distributed production system. However, the carbon emissions generated during transport between plants are not considered. Therefore, attention should be paid to the greenhouse gas generated by the transport of construction material, and a model is proposed to support decision-making in production methods that considers even the carbon emission generated in transport between material production processes. The main findings of this research are as follows.

1) Through an analysis of the production method of construction material in a plant and the freight transport structure, the efficiency of a base center in the divided production process was examined, and the impact of the transport sector on the environment was reviewed. To perform the study, previous process evaluation studies of the construction structure were reviewed and on this basis it was found that there was no consistent greenhouse gas estimation method, and the greenhouse gas emission estimation methods for the transport sector were analyzed.

2) A model for transport cost and carbon emission generated either in a batch production system by which all the processes are carried out in the manufacture and production phase or in a distributed production by which part or all of each unit process is outsourced is defined. On this basis, a production and transport integration model is built in consideration of carbon emissions, which can be utilized as fundamental data when selecting a production method.

3) A representative factory produced material, and the unit type aluminum curtain wall was selected as the target material for the model verification to review the utilization plan for a model. When the travel distance is longer, the cost can be reduced or increased depending on the production method and process system.

4) It was revealed that cost reduction was achieved when the material was initially produced in a plant in the city of Goyang, and carried into the 
construction site in Busan, the pre-glazing work was done first and then the double layer glass was delivered to a factory near Busan, and then the aluminum process and glazing process were performed.

Based on the research findings, a production system design model can be built in consideration of the carbon emission generated from all transport through the appropriate management of the transport method and location of assembly plants, and the selection of a distributed production system for construction material. However, of the two factors selected to be considered in the total cost estimation, transport cost and environmental cost, it was proven that the model was mostly affected by the transport cost, and there are limitations to its success as an integrated model. However, in terms of environmental cost, the model was considerably affected by the carbon transaction cost, and showed a noticeable change according to the carbon emission coefficient. This suggests the need for a carbon emission coefficient certified by the Korean government.

It is expected that the model suggested in this study will be utilized in planning a material production system appropriate for construction site conditions, and in particular can be used to determine an economical transport system by selecting the optimal location of plants at midpoint. Furthermore, it also contributes to national attempts to reduce carbon emission and helps companies to secure competence by applying and managing a dry material production system.

\section{Acknowledgement}

This research was supported by the National Research Foundation of Korea(NRF) grant funded by the Korea government(MEST) (No. 20120002344).

\section{References}

1. Williamson OE. The Economic Institutions of Capitalism, 2nd ed. New York (NY): A Division of Macmillan Inc.; 1985 p. $1-2$

2. Jeong YS. A Study on Prediction Model of Carbon Dioxide Emission in Life Cycle for Residential Buildings, [dissertation]. Seoul(Korea): University of Seoul; 2010. 65 p.

3. Allison A, Bryan B. Prefab, 1st ed. Layton (UT): Gibbs Smith Publisher; 2002. p.12-13

4. Kim YS. A Development of Automated Life-Cycle Management System for Curtain Wall Process for High-Rise Buildings based on Supply Chain Management. Seoul (Korea): Korea Institute of Construction Engineering and Management; 2006. p. 123-6.

5. Park YS, Choi HR, Kim HS, Park NK, Cho JH, Kang MH. A Decision Support System for the Third-party Logistics Optimal Transportation Network Planning. Proceeding of the Korea Society of Management Information Systems; 2006 June 16; Seoul (Korea). Seoul (Korea): KICEM; 2006. p. $965-74$

6. Figueiredo JN, Mayerle SF. Designing Minimum-cost Recycling Collection Networks with Required Throughput. Transportation Research. 2008 September;44(5):731-52.

7. Erkut E, Neuman S. Analytical Models for Locating Undesirable Facilities. European Journal of Operational Research 1989 June;40(3):275-91.

8. Kim EM. A Study of Physical Distribution Channel Choice Modeling Focused on Domestic Goods [master's thesis]. Seoul (Korea): the University of Seoul; 2009. p. 72.

9. Lee JS. A study on the Impact of Partnership with Contractors on the Project Performance in the Outsourcing of the Construction Industry [master's thesis]. Seoul (Korea): Yonsei University; 1999. p. 26-7.

10. Jang MH. Development of a Materials Management System Considering Construction Supply Chain Management. Journal of the Korea Institute of Building Construction 2009 October;9(5):89-95.

11. Agapiou A, Clausen LE, Norman G, Flanagan R. The role of Logistics in the Materials Flow Control Process, Construction Management and Economics. 1998 March;16(2):131-7.

12. Faulin J, Ubeda S, Lera F, Pintor JM, San Miguel J. 
Optimization of Road Freight Transportation in Spain Taking Into Account Environmental Criteria [Internet]. 2007[cited 2012 Oct 10]. Available from:

http://www.cnc-logistica.org/congreso-cnc/documentos/100

13. IPCC. Revised Guidelines for National Greenhouse Gas Inventories(IPCC2006), IGES, Japan; 2006.

14. Shin TH, Chin SY, Yoon SW, Kwon SW, Kim YS. A SOA-based Application Model for Building Intelligent Construction Supply Chain Management Framework. Proceeding of KICEM Annual Conference; 2008 Novemeber 7-8; Seoul (Korea). Seoul (Korea): KICEM; 2008. p. 735-9.

15. Ahn BJ, Yang JY, Baik JK, Kim JJ. Developing a Transportation and Procurement System for Curtain-Wall Materials focused on JTT Management. Journal of the Archtectural Institute of Korea 2003 August;19(8):153-62.

16. Lee SH. A Study on Improvement of High-rise Curtain Wall Life-cycle Process Using Value Stream Mapping. [master's thesis]. Seoul (Korea): KwangWoon University; 2006. p. 83-91. 